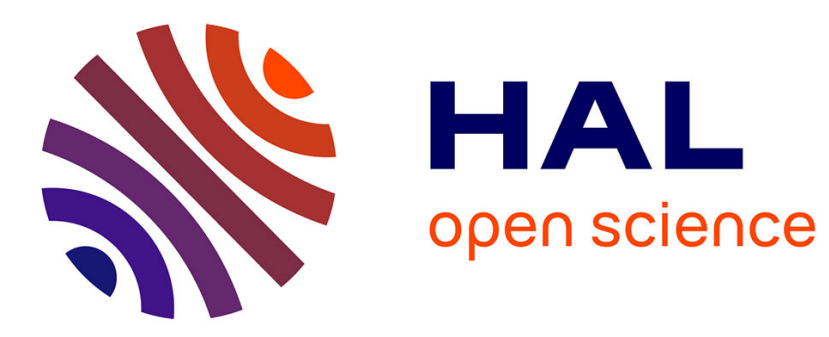

\title{
Prediction of stress induced by heterogeneous oxidation: Case of epoxy/amine networks
}

\author{
Esteve Ernault, Justin Dirrenberger, Emmanuel Richaud, Bruno Fayolle
}

\section{To cite this version:}

Esteve Ernault, Justin Dirrenberger, Emmanuel Richaud, Bruno Fayolle. Prediction of stress induced by heterogeneous oxidation: Case of epoxy/amine networks. Polymer Degradation and Stability, 2019, 162, pp.112-121. 10.1016/j.polymdegradstab.2019.02.019 . hal-02086883

\section{HAL Id: hal-02086883 https://hal.science/hal-02086883}

Submitted on 1 Apr 2019

HAL is a multi-disciplinary open access archive for the deposit and dissemination of scientific research documents, whether they are published or not. The documents may come from teaching and research institutions in France or abroad, or from public or private research centers.
L'archive ouverte pluridisciplinaire HAL, est destinée au dépôt et à la diffusion de documents scientifiques de niveau recherche, publiés ou non, émanant des établissements d'enseignement et de recherche français ou étrangers, des laboratoires publics ou privés. 


\title{
Prediction of stress induced by heterogeneous oxidation: Case of epoxy/amine networks
}

\author{
Esteve Ernault, Justin Dirrenberger, Emmanuel Richaud, Bruno Fayolle* \\ PIMM UMR 8006, Arts et Métiers ParisTech, CNRS, CNAM, 151 bd de l'Hôpital, Paris, France
}

\begin{abstract}
A B S T R A C T
A methodology to predict the formation of superficial stress during the diffusion-limited oxidation of thick epoxy/amine samples is proposed. This quantitative methodology is based on the understanding of mechanisms responsible for this stress lead to superficial micro-cracks. The first step consists of simulating the homogeneous oxidation on the surface of thick samples. The extent of oxidation is assessed through the concentration of oxidation products as amide groups measured using Fourier-transform infrared spectroscopy (FTIR). These experimental results are compared to simulations obtained from a kinetic model based on a close loop mechanistic scheme in chain oxidation. Shrinkage and tensile behavior changes are correlated with an oxidation tracer, being amide groups in our case. The second step considers diffusion-limited oxidation in thick samples where the gradients of oxidation products characterized through thickness by micro-FTIR are simulated by coupling the previous kinetic model with oxygen diffusion. Finally, the gradient of strain and stress induced by oxidation of a thick epoxy/ amine sample is simulated by inserting the mechanical behavior modifications and shrinkage gradient associated with the amide gradient in finite element code $\left(\right.$ Abaqus $\left.^{\circledR}\right)$. As a result, it is shown that it is possible to predict the superficial stress level as a function time/temperature of exposure and sample geometry.
\end{abstract}

Keywords:

Oxidation

Epoxy

Gradient

Finite element method

\section{Introduction}

It has been known for decades that oxidation damages polymers or polymer matrix composites [1], with long-term damage tending to limit their "lifetime" [2]. As the oxidation process is a major concern for polymer durability, the prediction of its kinetic based on accelerated tests is still a challenge. Most of the time, accelerated tests involve accelerating the exposure temperature. However, a temperature increase can modify the competition between mechanisms involved in the entire degradation process. The best example is the oxidation of thick samples where the oxidation kinetic is controlled by the diffusion of reactive molecular species here, oxygen - often called diffusion-limited oxidation (DLO) [3-5]. The DLO process is then characterized by the appearance of a superficial oxidized layer. The thickness of this oxidized layer (TOL) can be assessed in a first approach using the following scaling law: $T O L \sim\left(D_{\mathrm{O} 2} / K\right)^{\frac{1}{2}}$, where $\mathrm{D}_{\mathrm{O} 2}$ is the oxygen diffusion coefficient and $\mathrm{K}$ the relative oxidation rate, with both quantities $\mathrm{D}_{\mathrm{O} 2}$ and $\mathrm{K}$ being activated by temperature in a different manner. However, this scaling is only valid for first order oxidation kinetic assuming a stationary state which is not true in many cases.

The consequence of DLO is an inhomogeneous distribution of the oxidation products, which are concentrated in the layer closest to the surface [6]. As oxidation product formation is associated with macromolecular changes such as chain scission and crosslinking, a gradient of physical and mechanical properties is then expected. For most polymers, oxidation leads to mass loss and density increase, with the latter being due to oxygen grafting. As a result, a shrinkage strain profile proportional to the oxidation product profile is established. The assessment of this shrinkage profile is experimentally complex, since the unoxidized sample core limits the macroscopic strain [7]. For instance, measurements of matrix shrinkage in composite surfaces have been performed using interferometric microscopy [8]. Another possible way is to characterize the stress field induced by the shrinkage gradient by inverse analysis $[9,10]$. However, this approach requires knowledge of the local mechanical behavior through the oxidized layer.

In this study, we propose a new methodology to predict the stress and strain field induced by the DLO process. This 
methodology is based on a multi-scale approach involving main modifications driven by this process. For this purpose, the methodology follows the steps described below:

1. The intrinsic oxidation rate is assessed for a given exposure temperature by identifying a relevant marker at the molecular scale: for instance, an oxidation product that is easily measurable by Fourier-transform infrared spectroscopy (FTIR). To ensure that oxidation is intrinsic to the polymer, accelerated tests are performed on thin films to confirm that oxidation is not controlled by diffusion. Although some authors have proposed to directly assess oxidation rate by oxygen uptake [11], we propose here the FTIR method, since it can also be coupled with microscopy to measure the oxidation gradient as outlined in step 3 below.

2. Kinetic modeling of the relevant marker is built based on a closed-loop oxidation mechanistic scheme. The modeling parameters are determined from experimental data obtained in step 1 for a given exposure temperature. Our approach here is to determine kinetic parameters by the inverse method for the given polymer [12].

3. On the thin samples where oxidation is homogeneous, some correlations between oxidation markers and physical properties are established. Two main properties are taken into account as a function of oxidation extent: the first is the shrinkage associated with mass and density changes, and the second is the mechanical behavior. While modulus change is obviously required, the changes of nonlinear polymer behavior should be considered to predict stress state as a function of the strain induced by shrinkage.

4. For the same exposure temperature as in step 1, thick samples are exposed to identify the DLO progress. Several experimental tools such as microscopy [13], FTIR, and electron spin resonance imaging [14] allow us to characterize the oxidation gradient through thickness.

5. The previous kinetic modeling is made more complex by adding oxygen diffusion. Using the oxygen diffusion value, oxidation profile simulations may be performed and the results compared to the experimental oxidation marker profile obtained in step 3. This step allows us to check the validity of the kinetic modeling, including oxygen diffusion. After validation, the kinetic modeling allows us to simulate marker profiles as a function of time by interpolation.

6. Oxidation marker profiles are introduced in the finite element (FE) code for a given exposure duration. Using step 3, local induced strain and mechanical behavior are associated with a level marker.

7. Finally, FE simulations give access to the stress-strain field for a given exposure duration. This approach is applied not only in 1D but also in 2D to investigate the influence of geometry on the stress-strain field induced by the DLO.

Our purpose here is to illustrate this approach by applying our methodology to the oxidation of an epoxy/amine system as a material model. Epoxy/amine system is indeed a good candidate, since it shows moderate ductile behavior to ease the mechanical analysis. Furthermore, the oxidation process of this system has already been studied in the literature [15].

\section{Materials and methods}

\subsection{Materials and ageing procedure}

Bisphenol A diglycidyl ether (DGEBA; DER 332 - CAS 1675-54-3 - ref 31185 supplied by Sigma Aldrich) has a degree of polymerization of $\mathrm{n}=0$ and an average molecular mass equal to $340 \mathrm{~g} \mathrm{~mol}^{-1}$. It was cured with isophorone diamine (IPDA; CAS 2855-13-2 - ref 118184 supplied by Sigma Aldrich, $\mathrm{M}=170.3 \mathrm{~g} \mathrm{~mol}^{-1}$ ) in stoichiometric ratio, i.e. $100 \mathrm{~g}$ of DER $332+25$ g IPDA.

Differential scanning calorimetry scans of this mixture show the classical exothermal peak with a specific cure enthalpy $\mathrm{ca} 400 \mathrm{Jg}^{-1}$ with a maximal peak temperature of $117^{\circ} \mathrm{C}$ and an onset temperature at around $60^{\circ} \mathrm{C}$. Samples were cured under vacuum at $60^{\circ} \mathrm{C}$ during $2 \mathrm{~h}$ and then post-curing at $160^{\circ} \mathrm{C}$. The full cure was checked with the loss of the $914 \mathrm{~cm}^{-1}$ peak being attributed to the epoxide group. After the curing cycle, $\mathrm{T}_{\mathrm{g}}$ was found close to $166^{\circ} \mathrm{C}$, which confirmed that the samples had achieved complete crosslinking. This aspect is crucial to confirm that modifications observed during ageing are necessarily associated with an oxidation mechanism.

To accelerate the oxidation process, thin and thick sample exposures were performed in air at $110^{\circ} \mathrm{C}$ in ventilated ovens regulated at $\pm 3{ }^{\circ} \mathrm{C}$.

\subsection{Characterization of homogenously oxidized samples (thin samples)}

Oxidative products were followed using FTIR. FTIR spectroscopy in transmission mode was performed on freestanding films of a thickness between 10 and $20 \mu \mathrm{m}$ using a Frontier spectrophotometer (PerkinElmer) in the 550 to $4000 \mathrm{~cm}^{-1}$ wavenumber range by averaging 16 scans at a $4 \mathrm{~cm}^{-1}$ resolution. Spectra were interpreted using Spectrum software (PerkinElmer) using a baseline correction on following points $3700 \mathrm{~cm}^{-1} ; 2472 \mathrm{~cm}^{-1} ; 2000 \mathrm{~cm}^{-1}$. Since absorbance $(\mathrm{A})$ value is assessed from peak height at a given wavenumber, the concentration of oxidation products was calculated using the Beer Lambert law:

$A=\varepsilon_{\lambda}^{*} l * C_{\lambda}$

where $\mathrm{A}$ is the absorbance (corrected by the baseline value), $\varepsilon_{\lambda}$ (l $\mathrm{mol}^{-1} \mathrm{~cm}^{-1}$ ) the molar absorptivity equal to $\varepsilon_{1656}=4701 \mathrm{~mol}^{-1} \mathrm{~cm}^{-1}$ for amides [16], $1(\mathrm{~cm})$ the thickness of the film, and $C_{\lambda}\left(\mathrm{mol} \mathrm{l}^{-1}\right)$ the concentration of the considered species.

Density was measured on a XS203S density scale (Mettler Toledo) with an accuracy of $\pm 0.005 \mathrm{~g}$. For our purpose, the density of the solvent had to be a lower than that of the epoxy/amine networks (close to $1.2 \mathrm{~g} \mathrm{~cm}^{-3}$ ) to make the measurement more accurate. We chose acetone with a density of $0.79 \mathrm{~g} \mathrm{~cm}^{-3}$ (and assumed that time for measurement was short enough to avoid solvent swelling or short chain extraction). Two samples with a mass of at least $100 \mathrm{mg}$ (square $2 \times 2 \mathrm{~cm}^{2}$ ) were tested when the mass and density of each network were monitored at each exposure condition to verify the repeatability of the measurements obtained.

Uniaxial tensile tests were carried out on an Instron ${ }^{\circledR} 5881$. Dumbbell specimens were stressed at an imposed displacement speed of $1 \mathrm{~mm} \mathrm{~min}^{-1}$, with the forces being measured by a cell with a capacity of $100 \mathrm{~N}$. A low displacement speed was chosen to consider mechanical behavior in static. The tests were performed in air-conditioned room at $23^{\circ} \mathrm{C}$. Specimens cut in films having their thickness close to $70 \pm 20 \mu \mathrm{m}$ in order to avoid heterogeneous oxidation. For each tensile test, exact thickness of specimen has been measured by using a length gauge Heidenhain with an accuracy of $0.2 \mu \mathrm{m}$.

\subsection{Characterization of heterogeneously oxidized samples (thick samples)}

A cross-section of $1 \mathrm{~mm}$ was cut in the middle of each thick 
sample. Microscopic observations were then made using the Axio imager 2 (Zeiss) microscope. Transmission and reflection images were compared to ensure that the value of oxidized layers observed in these two modes was consistent.

The second experimental technique for evaluating oxidized layers was the use of a microscope coupled to FTIR. For this, the thick samples oxidized at $110^{\circ} \mathrm{C}$ were cut transversely into films of 20-30 $\mu \mathrm{m}$ in thickness. Micro-FTIR makes it possible to carry out analyses in transmission with steps of $20 \mu \mathrm{m}$.

\section{Results}

\subsection{Homogenous oxidation}

To identify local behavior through thickness in the DLO regime, oxidation on thin films is required. On these films where oxidation can be considered to be homogenous, the aim is to assess oxidation progress and correlate the degradation level linked to oxidative product concentration with physical properties in terms of shrinkage and mechanical behavior in tensile mode.

\subsection{Oxidation progress: concentration of amide}

With FTIR, the oxidation progress for epoxy/amines can be followed using different oxidation products such as carbonyl and amide groups [15,17,18]. For the sake of simplicity, oxidation progress is followed here only using amide concentration as an oxidation tracer. Amide group formation is easily characterized by the growth of the peak height at $1656 \mathrm{~cm}^{-1}$ for epoxy/amine networks [19-21]. Fig. 1 shows amide formation during exposure at $110^{\circ} \mathrm{C}$ : after a maximum oxidation rate reached at around $200 \mathrm{~h}$ of exposure, amide formation slows down because of oxidation substrate consumption. The constitutive repetitive unit for DGBA IPDA is made of 2 DGEBA unit +1 IPDA unit. Its molar mass is $2 \times 340+168=848 \mathrm{~g} \mathrm{~mol}^{-1}$ and contains 6 methylenes likely to give an amide so that $[\mathrm{PH}] \sim 8 \mathrm{moll}^{-1}$. In other words, $1 \mathrm{moll}^{-1}$ corresponds to about $12 \%$ of amine linkages being oxidized. Given the results shown in this figure, amide concentration will be considered to be an oxidation tracer in the following sections.

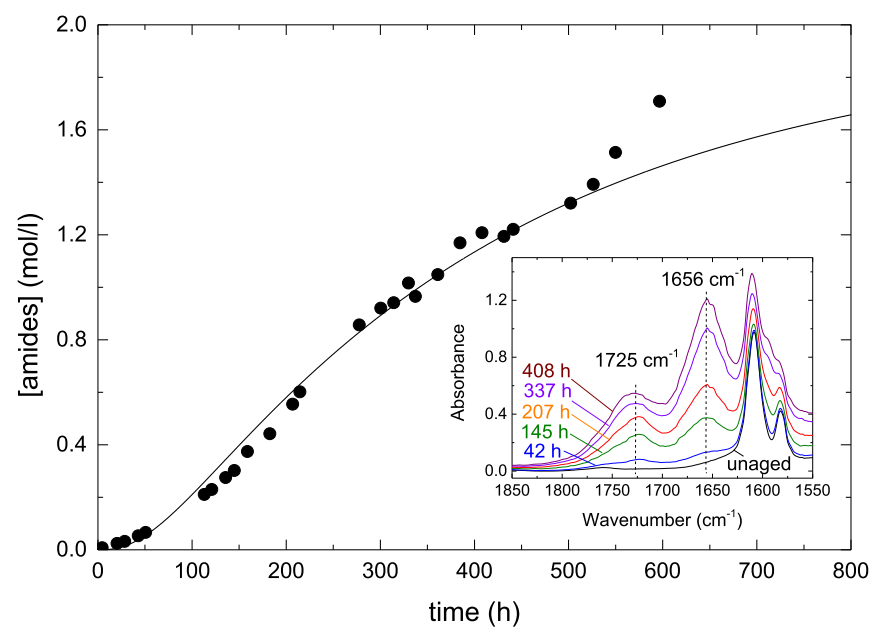

Fig. 1. Oxidation progress at $110^{\circ} \mathrm{C}$ in air followed by the concentration of amides for thin samples (thickness less than $100 \mu \mathrm{m}$ ) of DGEBA/IPDA; experimental results (dots) compared with kinetic model (continuous line).

\subsection{Shrinkage induced by oxidation}

It was reported that the oxidation of DGEBA/IPDA leads to a significant number of chain scissions [22]. At high conversion degrees, they are associated with the emission of volatile compounds such as $\mathrm{H}_{2} \mathrm{O}$ and $\mathrm{CO}_{2}$, and thus mass loss [7]. At the same time, it is expected that density will increase due to oxygen grafting associated with the oxidation mechanism [23]. It is easy to show that volumetric shrinkage (V) can be estimated from changes in mass $(\mathrm{m})$ and density $(\rho)$ using the following formula [24]:

$\frac{\Delta V}{V_{0}}=\frac{\Delta m}{m_{0}}-\frac{\Delta \rho}{\rho_{0}}$

It was observed that density changes were negligible compared to mass changes. As a result, volumetric shrinkage is mainly associated with a mass loss process in our case. Fig. 2 shows volumetric shrinkage as a function of amide concentration. Since a reasonable correlation is evidenced in this figure, we propose using this "structure-property" relationship in a first approach to establish a link between the oxidation tracer observed at the molecular scale and physical properties such as shrinkage. Although this relationship is empirical, it allows us to estimate the local shrinkage occurring in an oxidized layer. To confirm this correlation, a possible way could be to perform exposures at several temperatures or oxygen partial pressures and analyze volatile products chemically.

\subsection{Mechanical changes induced by thermo-oxidation}

To gain information about local mechanical properties in an oxidized layer, we investigate here the link between amide concentration and mechanical behavior for homogenously oxidized samples at several exposure times. For this purpose, stress strain curves of DGEBA/IPDA aged under air at $110^{\circ} \mathrm{C}$ for exposure times up to $240 \mathrm{~h}$ are shown in Fig. 3.

According to Fig. 3, it appears that oxidation clearly modifies the mechanical behavior after $111 \mathrm{~h}$ and $240 \mathrm{~h}$ of exposure. Note that after $240 \mathrm{~h}$ of exposure, the films are too brittle to perform tensile testing. It can be observed that the nonlinear character of the tensile curve for the unaged sample, which can be associated with viscous or plastic deformation, is removed during the oxidation process: although the modulus and stress at break increase, the drop in terms of strain at break and of toughness (from $3.5 \mathrm{~J} \mathrm{~cm}^{3}$ to $2.6 \mathrm{~J} \mathrm{~cm}^{3}$ ) from the beginning of exposure denotes an embrittlement process during oxidation as discussed in Ref. [22].

One of the most noticeable trends is the increase in the elastic modulus (at the mechanical test temperature, i.e. $23^{\circ} \mathrm{C}$ ). To evidence the relationship between the oxidation progress and modulus increase, the modulus is plotted as a function of amide concentration in Fig. 4.

The most probable explanation for this modulus increase is that the progressive disappearance of hydroxypropylether due to the thermal oxidation process induces the loss of the "plasticization" effect associated with the local mobility of hydroxypropylether and a subsequent increase in the elastic modulus [25,26]. Indeed, DGEBA/IPDA is mechanically tested here in the temperature domain between its glass transition $\left(\mathrm{T}_{\mathrm{g}}\right.$ equal to $\left.166^{\circ} \mathrm{C}\right)$ and subglass transition $\left(\mathrm{T}_{\beta}\right.$ equal to $-60^{\circ} \mathrm{C}$, measured by DMA see Ref. [18]). A previous study [27] has been reported the influence of oxidation on epoxy/amine network. In this paper authors have followed the glass transition temperature (in differential scanning calorimetry) during the oxidation of various epoxy/amine networks and especially in DGEBA/IPDA. In the case of DGEBA/IPDA, it has been shown that glass transition temperature dramatically 


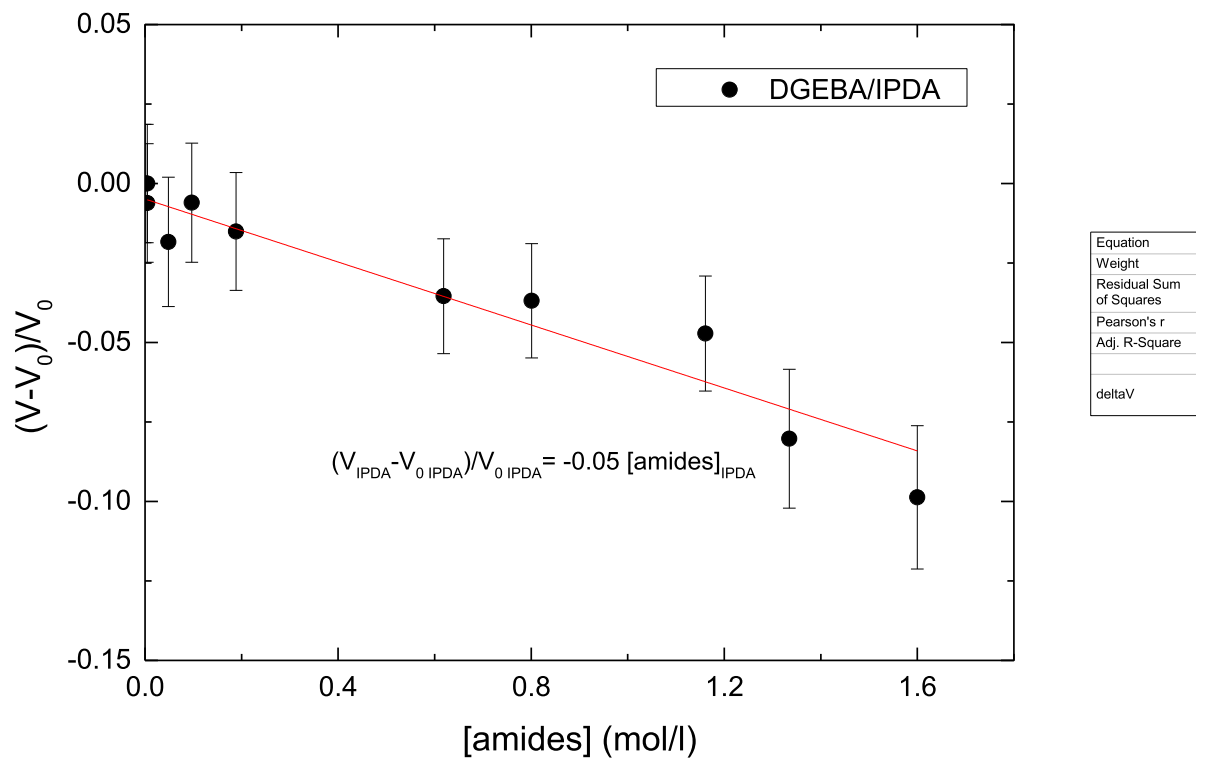

Fig. 2. Shrinkage changes of thin samples of DGEBA/IPDA at $110^{\circ} \mathrm{C}$ in air; the continuous line corresponds to the correlation used.

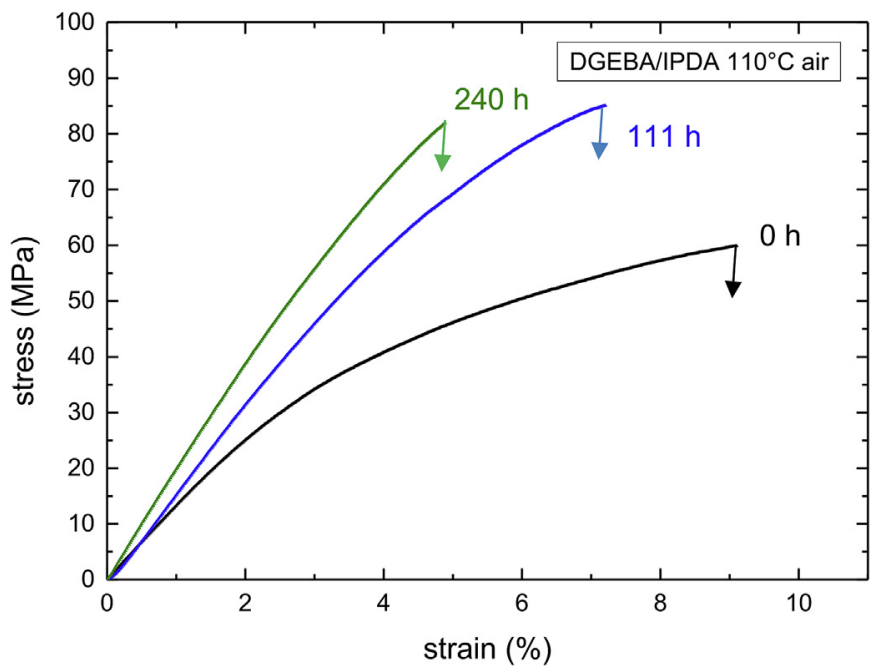

Fig. 3. Mechanical behavior of DGEBA/IPDA films in tensile mode before exposure and after $111 \mathrm{~h}$ or $0.2 \mathrm{moll}^{-1}$ for amide concentration and $240 \mathrm{~h}$ or $0.7 \mathrm{moll}^{-1}$ for amide concentration during exposure at $110^{\circ} \mathrm{C}$ in air.

decreases during the oxidation of this network. Using DiMarzio equation allows the authors of this study to conclude that oxidized DGEBA/IPDA undergoes mainly chain scission. However, one can note that even if DGEBA/IPDA mainly undergoes chain scissions that decrease its glass transition, $\mathrm{T}_{\mathrm{g}}$ remains above $145^{\circ} \mathrm{C}$ in the investigated time range $\left(0-240 \mathrm{~h}\right.$ at $\left.110^{\circ} \mathrm{C}\right)$.

\subsection{Diffusion-limited oxidation case}

One of the most striking features of the oxidative ageing of thick epoxy materials is the oxidation controlled by oxygen diffusion: the oxygen from air diffusing from the surface to the bulk mainly reacts at the surface layer. As a result, this oxygen can no longer contribute to oxidation in the core of the sample. This leads to the existence of an oxidized layer, as illustrated in several previous papers on epoxies and other polymers such as elastomers and thermoplastics $[10,19]$. Several methods to characterize the oxidized layer have

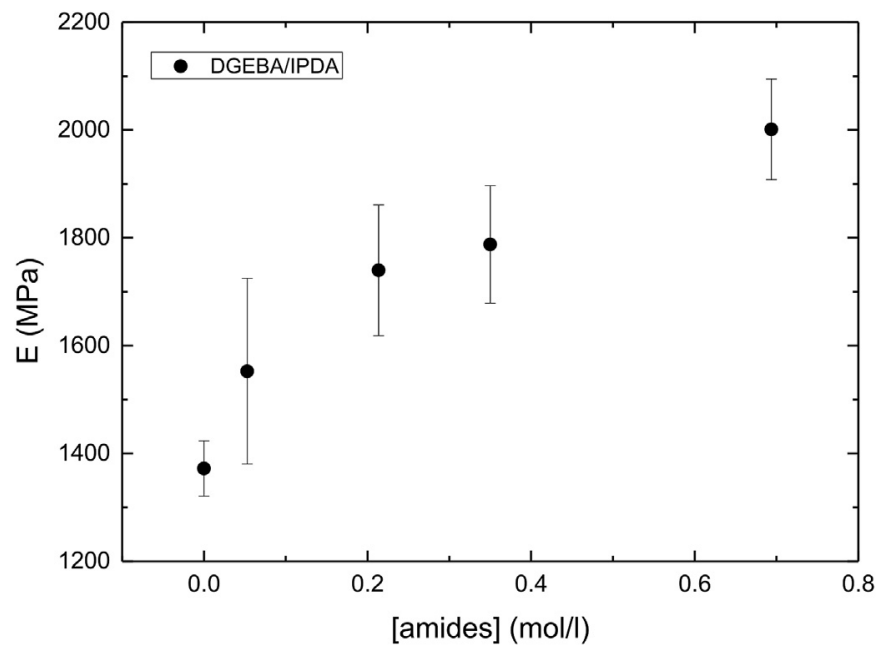

Fig. 4. Young's modulus changes of DGEBA/IPDA during oxidation at $110^{\circ} \mathrm{C}$ in air (assessed by amide concentration).

been proposed in the literature: optical microscopy through the thickness, mapping of oxidation products by micro-FTIR or hardness profile $[28,29]$. Here we propose characterizing the oxidation product profile across the thickness using micro-FTIR and optical microscopy.

Fig. 5 shows the amide concentration profiles for DGEBA/IPDA aged at $110^{\circ} \mathrm{C}$ under air after $800 \mathrm{~h}$. An optical microscopy image for the same sample is shown in the insert of Fig. 5. By using both techniques, the thickness of the oxidized layer (TOL) is around $200 \mu \mathrm{m}$.

\section{Discussion}

Based on experimental data, we propose to apply our modeling methodology to predict stress-strain induced by oxidation. The modeling is composed of two parts: the first is a kinetic model to simulate amide group formation as a function of exposure time in thin film and amide groups through the thickness of thick samples; 


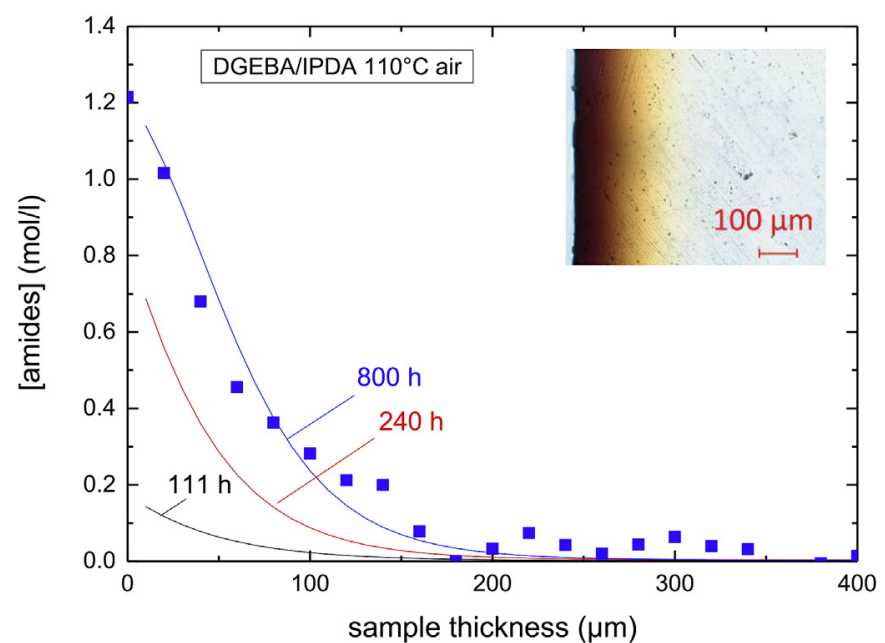

Fig. 5. Amide concentration profile in sample thickness of thick samples of DGEBA/ IDPA oxidized at $110^{\circ} \mathrm{C}$ in air; experimental results (scatter) compared to model (lines). The insert shows an optical microscope image of a sample oxidized at $110^{\circ} \mathrm{C}$ in air after $800 \mathrm{~h}$.

the second is dedicated to introducing the amide group profile in FE code and its corresponding local properties in terms of shrinkage and mechanical behavior.

\subsection{Kinetic modeling for oxidation at the molecular scale}

It was well established that the oxidation mechanism of epoxies can be represented by the following mechanistic scheme [13]:

$\mathrm{POOH} \rightarrow 2 \mathrm{P}^{\circ}+\mathrm{P}=\mathrm{O}+\mathrm{V} \mathrm{k}_{1}$

$\mathrm{P}^{\circ}+\mathrm{O}_{2} \rightarrow \mathrm{POO}^{\circ} \mathrm{k}_{2}$

$\mathrm{POO}^{\circ}+\mathrm{PH} \rightarrow \mathrm{POOH}+\mathrm{P}^{\circ} \mathrm{k}_{3}$

$\mathrm{P}^{\circ}+\mathrm{P}^{\circ} \rightarrow$ inactive products $\mathrm{k}_{4}$

$\mathrm{POO}^{\circ}+\mathrm{P}^{\circ} \rightarrow$ inactive products $\mathrm{k}_{5}$

$\mathrm{POO}^{\circ}+\mathrm{POO}^{\circ} \rightarrow$ inactive products $+\gamma_{6} \mathrm{P}=\mathrm{O}+\mathrm{O}_{2} \mathrm{k}_{6}$

Where:

- $\mathrm{P}^{\circ}, \mathrm{POO}^{\circ}, \mathrm{POOH}$, and $\mathrm{PH}$ are respectively alkyl, peroxy radicals, hydroperoxides, and oxidizable sites;

- $\mathrm{P}=\mathrm{O}$ and $\mathrm{V}$ represent amide products (observed from FTIR) and volatile compounds;

- $\mathrm{k}_{\mathrm{i}}$ and $\gamma_{\mathrm{i}}$ are the rate constants and yields of elementary reactions. Each is expected to have a physical sense. The method for their determination can be summarized as follows.

$\mathrm{k}_{2}$ corresponds to the reaction between an alkyl radical $\left(\mathrm{P}^{\circ}\right)$ and oxygen (which is a biradical). This rate is expected to be relatively high $[30,31]$. It is shown not to influence the simulation runs provided that its value is physically reasonable $\left(10^{6}-10^{9} 1 \mathrm{~mol}^{-1} \mathrm{~s}^{-1}\right)$. The value was fixed here at $10^{6} 1 \mathrm{~mol}^{-1} \mathrm{~s}^{-1}$ as for polyamide [30,32].

$\mathrm{k}_{3}$ describes the reaction of hydrogen abstraction by a peroxy radical. It obeys a structure-property relationship. Its value is linked to the strength (i.e., bond dissociation energy or BDE) of the broken $\mathrm{C}-\mathrm{H}$ according to the relationships proposed by Korcek [33]: since $\log _{10} \mathrm{k}_{3}=16.4-0.0477^{*} \mathrm{BDE}(\mathrm{C}-\mathrm{H}), \mathrm{E}_{3}=0.55 \times(\mathrm{BDE}(\mathrm{C}-\mathrm{H})-261.6)$. $\mathrm{BDE}$ was approximated to be equal to $381 \mathrm{~kJ} \mathrm{~mol}^{-1}$ so that $\mathrm{E}_{3}=60 \mathrm{~kJ} \mathrm{~mol}^{-1}$ and $\mathrm{k}_{3}\left(110^{\circ} \mathrm{C}\right)=3.51 \mathrm{~mol}^{-1} \mathrm{~s}^{-1}$.

$\mathrm{k}_{4}, \mathrm{k}_{5}$, and $\mathrm{k}_{6}$ can be selectively determined from ageing tests under several oxygen pressures [34]. In short, under enhanced oxygen pressure, $\mathrm{P}^{\circ}$ radicals are quickly scavenged by $\mathrm{O}_{2}$ and instantaneously generate $\mathrm{POO}^{\circ}$ radicals so that the termination $\mathrm{POO}^{\circ}+\mathrm{POO}^{\circ}$ predominates, and its rate constant can be estimated selectively from the maximal oxidation rate value. Subsequently, $\mathrm{k}_{4}$ and $\mathrm{k}_{5}$ are used to simulate the degradation under lower oxygen pressure where $\mathrm{P}^{\circ}+\mathrm{POO}^{\circ}$ and $\mathrm{P}^{\circ}+\mathrm{P}^{\circ}$ reactions are involved. They thus verify the ranking [5,35]: $\mathrm{k}_{4}>\mathrm{k}_{5} \gg \mathrm{k}_{6}$.

At last, according to our assessment methodology, $\mathrm{k}_{1}$ is adjusted from the degradation curves during the early exposure time. Here it corresponds to the thermal decomposition of hydroperoxides present at the heteroatom position. Its value is thus expected to be higher than in polyolefins (for example) where no such inductive effect has a destabilizing effect [31].

The values for the rate constants are given in Table 1.

The mechanistic scheme leads to the following differential system:

$$
\begin{aligned}
\frac{d\left[P^{\circ}\right]}{d t}= & 2 k_{1}[\mathrm{POOH}]-k_{2}\left[P^{\circ}\right]\left[\mathrm{O}_{2}\right]+k_{3}\left[\mathrm{POO}^{\circ}\right][\mathrm{PH}]-2 k_{4}\left[\mathrm{P}^{\circ}\right]^{2} \\
& -k_{5}\left[\mathrm{P}^{\circ}\right]\left[\mathrm{POO}^{\circ}\right]
\end{aligned}
$$

$\frac{d\left[\mathrm{POO}^{\circ}\right]}{d t}=k_{2}\left[\mathrm{P}^{\circ}\right]\left[\mathrm{O}_{2}\right]-k_{3}\left[\mathrm{POO}^{\circ}\right][\mathrm{PH}]-k_{5}\left[\mathrm{P}^{\circ}\right]\left[\mathrm{POO}^{\circ}\right]-2 k_{6}\left[\mathrm{POO}^{\circ}\right]^{2}$

$\frac{d[\mathrm{POOH}]}{d t}=-k_{1}[\mathrm{POOH}]+k_{3}\left[\mathrm{POO}^{\circ}\right][\mathrm{PH}]$

The oxygen concentration in the surface layer is expected to be constant as provided in Henry's law $\left[\mathrm{O}_{2}\right]=\mathrm{S}_{\mathrm{O} 2} \cdot \mathrm{P}_{\mathrm{O} 2}$. As a result, the outputs of the model are the concentration in reactive species $\left(\mathrm{P}^{\circ}\right.$, $\left.\mathrm{POO}^{\circ}, \mathrm{POOH}\right)$. The concentration in amides is obtained from their "post-treatment" by integrating the following equation:

$\frac{d[P=O]}{d t}=k_{1}[\mathrm{POOH}]+\gamma_{6} k_{6}\left[\mathrm{POO}^{\circ}\right]^{2}$

The numerical solution of this 1D model is performed in time and space using a numerical solver (Matlab ODE 23s) with the following boundary conditions partly justified elsewhere [36]:

At $\mathrm{t}=0,\left[\mathrm{P}^{\circ}\right]=\left[\mathrm{POO}^{\circ}\right]=0,[\mathrm{POOH}]_{0}=10^{-3} \mathrm{moll}^{-1},[\mathrm{PH}]_{0}=2 /$ $\mathrm{M}_{\mathrm{CRU}}$ where $\mathrm{M}_{\mathrm{CRU}}$ is the molecular mass of the constitutive repetitive unit of the DEGBA/IPDA network. $[\mathrm{PH}]_{0}$ value corresponding to the substrate concentration value for our epoxy network is reported in Table 2.

The material parameters for oxygen solubility and diffusivity

Table 1

\begin{tabular}{|c|c|c|c|c|c|c|}
\hline $\mathrm{k}_{1}$ & $\mathrm{k}_{2}$ & $\mathrm{k}_{3}$ & $\mathrm{k}_{4}$ & $\mathrm{k}_{5}$ & $\mathrm{k}_{6}$ & $\Upsilon_{6}$ \\
\hline $\mathrm{s}^{-1}$ & $1 \mathrm{~mol}^{-1} \mathrm{~s}^{-1}$ & $1 \mathrm{~mol}^{-1} \mathrm{~s}^{-1}$ & $1 \mathrm{~mol}^{-1} \mathrm{~s}^{-1}$ & $\mathrm{~L} \mathrm{~mol}^{-1} \mathrm{~s}^{-1}$ & $1 \mathrm{~mol}^{-1} \mathrm{~s}^{-1}$ & \\
\hline $1 \times 10^{-5}$ & $10^{6}$ & 2.25 & $2.5 \times 10^{10}$ & $2.25 \times 10^{10}$ & $2 \times 10^{3}$ & 0.5 \\
\hline
\end{tabular}

Rate constants used for the simulation of experimental results at $110^{\circ} \mathrm{C}$. 
Table 2

Material parameters used for simulations.

\begin{tabular}{llll}
\hline$[\mathrm{PH}]_{0}$ & $\mathrm{~S}_{\mathrm{O} 2}$ & $\mathrm{D}_{\mathrm{O} 2}\left(23^{\circ} \mathrm{C}\right)$ & $\mathrm{D}_{\mathrm{O} 2}\left(110^{\circ} \mathrm{C}\right)$ \\
\hline $\mathrm{lol} \mathrm{l}^{-1}$ & $\mathrm{~mol} \mathrm{l}^{-1} \mathrm{~Pa}^{-1}$ & $\mathrm{~m}^{2} \mathrm{~s}^{-1}$ & $\mathrm{~m}^{2} \mathrm{~s}^{-1}$ \\
5.8 & $2.3 \times 10^{-7}$ & $1.3 \times 10^{-13}$ & $7.3 \times 10^{-13}$ \\
\hline
\end{tabular}

$\left(\mathrm{S}_{\mathrm{O} 2}, \mathrm{D}_{\mathrm{O} 2}\right)$ are given in Table 2 . Let us specify that.

- $\mathrm{s}_{\mathrm{O} 2}$ and $\mathrm{D}_{\mathrm{O} 2}$ were measured at room temperature using a standard permeameter [37];

- S02 was considered to remain almost constant with temperature, whereas $\mathrm{D}_{\mathrm{O} 2}$ value at $110^{\circ} \mathrm{C}$ was based on the literature $[13,38]$ as detailed in Table 2. For more information on the Arrhenius behavior of both quantities, see Ref. [39]. Let us note that the solubility of oxygen is not really constant with temperature. However, a recent paper illustrates the solubility change with temperature in epoxies and show they are really minor compared to diffusivities ones [39] and shows that values of solubility remain in the same decade even with $100^{\circ} \mathrm{C}$ temperature changes. The real activation energy for solubility for DGEBA/IPDA system is unknown which arises the question of the effect of $\left[\mathrm{O}_{2}\right]$ misestimation on our simulations. As it can be seen in the differential system, the oxygen concentration is always associated to the rate constant $\mathrm{k}_{2}$ so that an overestimation of $\left[\mathrm{O}_{2}\right]$ can be compensated by an underestimation of $\mathrm{k}_{2}$.

Fig. 1 shows a comparison between experimental and simulated amide formation. Although $\mathrm{k}_{1}, \mathrm{k}_{6}$, and $\gamma_{6}$ parameters values were optimized using the inverse method, one can observe a good data agreement, especially at the beginning of exposure where a slight auto-acceleration is observed. After $500 \mathrm{~h}$, a deviation can be observed between experimental data and the kinetic modeling: at the degree of oxidation. This deviation at this stage can be explained by the fact oxidation can lead to secondary products (resulting from the conversion of primary products into by products differing by their molar absorptivity, or originating from other sites than methylene in $\alpha$ position of nitrogens ...), the formation of which being not an output of the kinetic model we used.

In the case of thick samples, the consumption of oxygen is expressed by the following equation that describes the coupling between oxygen absorption (reaction 2)/release (reaction 6 ) due to oxidation and oxygen diffusion $[4,6]$ :
$\frac{d\left[O_{2}\right]}{d t}=-k_{2}\left[P^{\circ}\right]\left[O_{2}\right]+k_{6}\left[P O O^{\circ}\right]^{2}+D_{O 2} \cdot \frac{\partial^{2}\left[O_{2}\right]}{\partial z^{2}}$

Let us precise that it was assumed that $\left[\mathrm{O}_{2}\right]$ and $\mathrm{D}_{\mathrm{O} 2}$ remain constant with time i.e. oxidation level (even if, for example, a recent paper highlighted the effect of permeability change in photo oxidized PET [40]). The effect of chain scission/crosslinking and polarity changes on oxygen transfer properties in epoxies remains to be investigated. However, the fact that the model simulates fairly the order of magnitude of oxidized layer using rate constants fitting the kinetic curves at moderate conversion degrees and permeation parameters for unoxidized epoxies justifies, in a first approach, that the model can simulate the oxidation of bulky materials at moderate conversion values.

Fig. 5 shows amide concentration profiles in 1D for three exposure times: $111 \mathrm{~h}, 240 \mathrm{~h}$, and $800 \mathrm{~h}$ of exposure at $110^{\circ} \mathrm{C}$. First, one can observe a good agreement between simulates and experimental profiles for $800 \mathrm{~h}$ of exposure. The amide concentration gradient from the edge of the samples are well described, confirming the relevance of our approach. Simulated profiles for $111 \mathrm{~h}$ and $240 \mathrm{~h}$ as shown in Fig. 5 will be introduced in FE code in the following part.

\subsection{Finite element analysis for stress-strain field induced by oxidation}

To take into account neighboring and geometrical effects, which cannot be considered in the 1D semi-analytical approach, as well as the material behavior nonlinearities, we use FE analysis to simulate the mechanical fields induced by the oxidation of epoxy networks.

The amount of shrinkage due to oxidation locally depends on the sample geometry as well as the local material mechanical response, which evolves with the degree of oxidation. Given the nonlinearity involved, a simple rectangular 2D geometry (cf. Fig. 6) is considered for computing the stress and strain fields.

Geometry design, mesh generation, and FE are performed using the Abaqus FE package [41], standard version, with an implicit numerical scheme and 2D plane strain assumption. The generated mesh (Fig. 6) contains 4230 quadrilateral elements with 8 Gausspoints (CPE8), with a non-uniform size distribution, ranging from an element area of $1 \mathrm{~mm}^{2}$ at the center of the sample to $0.0001 \mathrm{~mm}^{2}$ at the corners, for a total size of $10 \times 20 \mathrm{~mm}$.

To solve the chemo-mechanical problem, we proceed as follows:

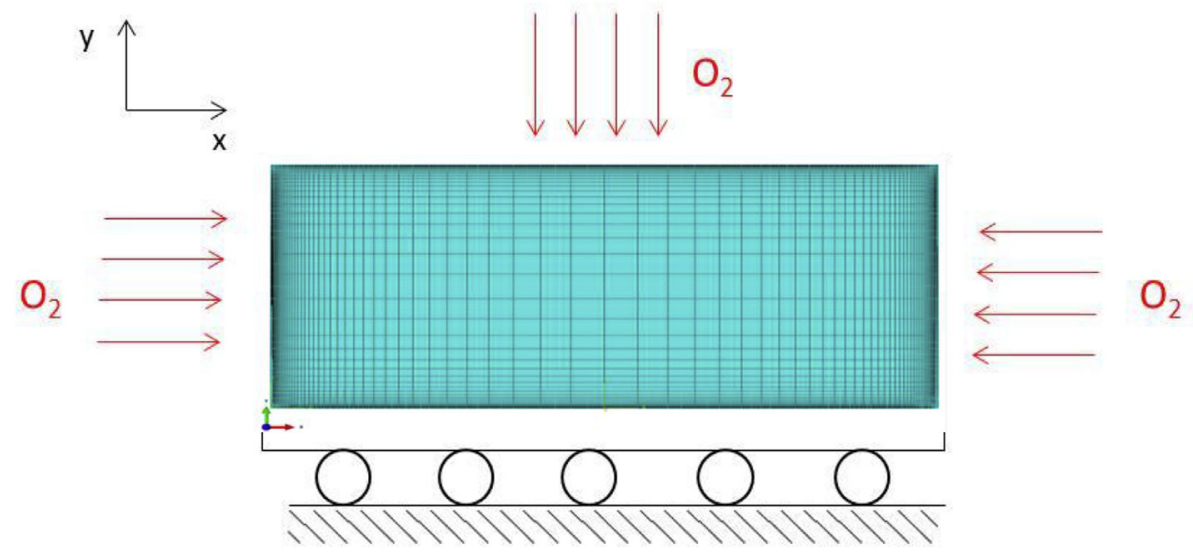

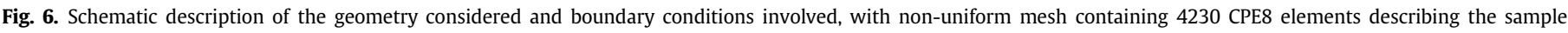
geometry. 
1. Sample size and oxidation time are considered.

2. Amide concentration is given according to the previous oxidation kinetics modeling.

3. Strain induced by oxidation is directly related to shrinkage according to our plane strain hypothesis, shrinkage being related with amide concentration in Fig. 2.

4. Material chemo-elastoplastic behavior (elastic modulus, plastic yield stress) varies with amide concentration according to the mechanical tests performed on the oxidized films, thus leading to heterogeneous mechanical fields.

The material behavior defined in Abaqus corresponds strictly to the nonlinear tensile curve measured experimentally for a given oxidation time and amide concentration, assuming that the Poisson ratio remains constant at 0.37 . For other oxidation times or amide concentrations, the nonlinear elastoplastic behavior is linearly interpolated proportionally to the amide concentration. No extrapolation is considered above the highest oxidation time ( $240 \mathrm{~h}$ in this work).
The lifetime prediction model of thick samples has already been validated from experimental data (Fig. 5). For this reason, the amide gradient concentration was included in the FE by fitting the model curve at $111 \mathrm{~h}$ and $240 \mathrm{~h}$ (Fig. 5).

According to our methodology, Figs. 7 and 8 show strain as a function of DGEBA/IPDA sample thickness for an oxidation time of $110 \mathrm{~h}$ and $240 \mathrm{~h}$, respectively. To illustrate geometric influence on oxidized layer shape, two orientations were considered: $90^{\circ}$ in a straight direction from the surface to the middle of the sample and $45^{\circ}$ from the corner to the middle of the sample. One can observe that the maximum strain at surface at $240 \mathrm{~h}$ in Fig. 8 is higher than the strain at break in Fig. 3. However, this experimental strain at break value is not an intrinsic property from failure point of view since these measurements are very sensitive to edge effects and cannot thus compare to the maximum strain predicted from the FE simulation.

To predict stress state at the surface of the oxidized sample, it is mandatory to have experimental data on the mechanical behavior of thin samples of DGEBA/IPDA. Two oxidation times are

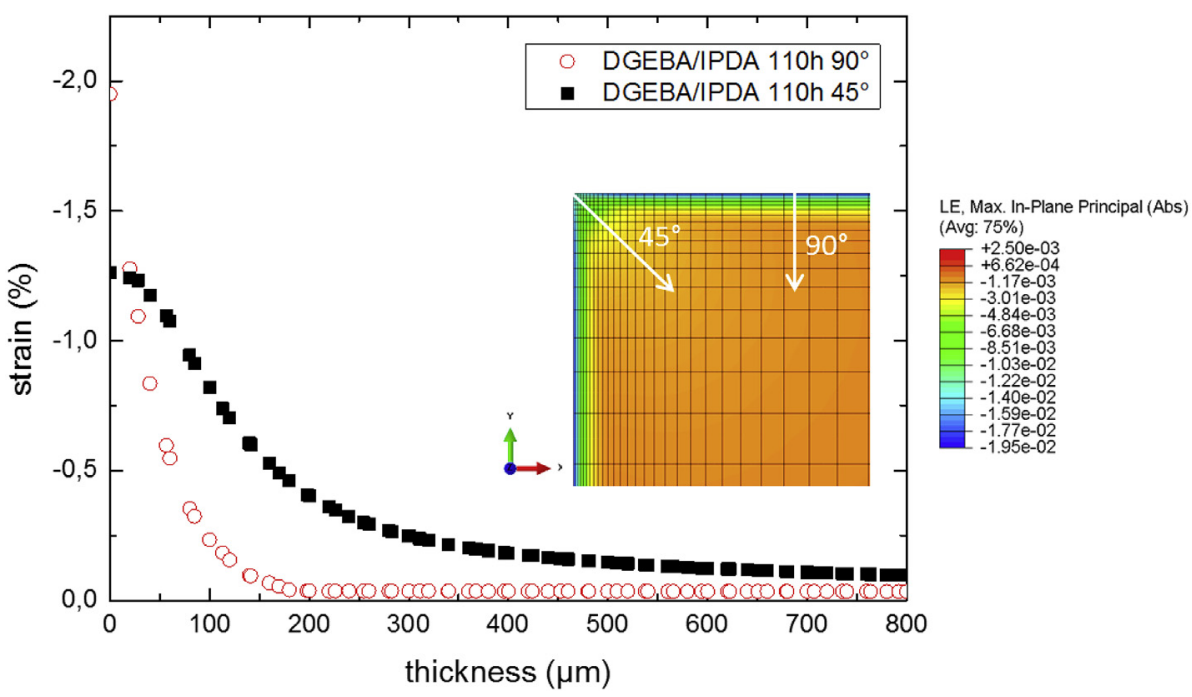

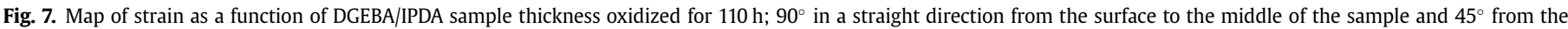
corner to the middle of the sample.

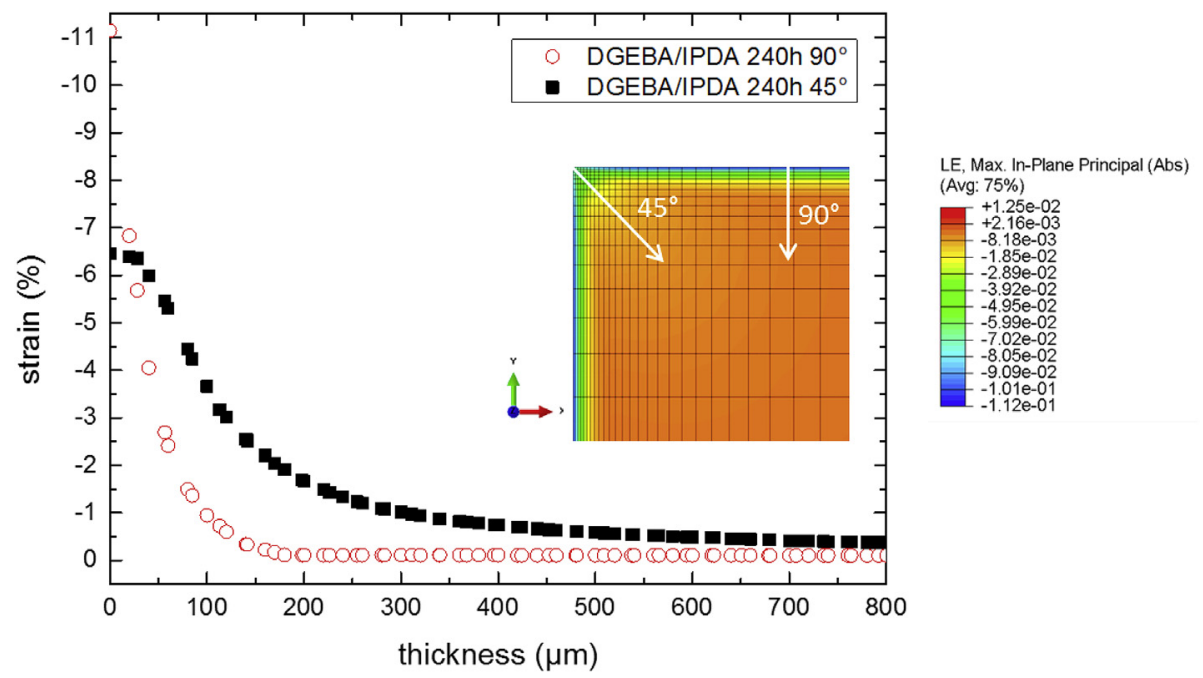

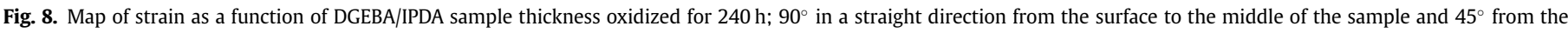
corner to the middle of the sample. 
considered (i.e., $110 \mathrm{~h}$ and $240 \mathrm{~h}$ ), as longer oxidation times result in samples that are too brittle to obtain accurate mechanical data in the tensile test.

Based on the stress-strain behavior identified in Fig. 3 and its interpolation for any oxidation conversion, the chemo-mechanical simulation is performed through FE analysis, yielding the mechanical fields shown in Figs. 9 and 10 for an oxidation time of $110 \mathrm{~h}$ and 240 h, respectively. As in Figs. 7 and 8, two orientations were considered: $90^{\circ}$ and $45^{\circ}$.

The structural effect of geometry can be seen on both the stress and strain maps, as the level of stress and shrinkage is lower in the corner (i.e., $45^{\circ}$ ) than at the center of the surfaces (i.e., $90^{\circ}$ ). This is due to the shrinkage equilibrium induced by the two perpendicular chemical loads as well as the corner that geometrically stiffens the sample. As a result, no cracking phenomenon is expected close to the corner as some authors have already observed experimentally [42].

Besides, a micro-meso damage model have been proposed to investigate the degradation of laminated composites under cyclic loading, including the effect of oxidation and the influence of the edge effect $[43,44]$. This approach considers oxidation leads to local reduction of tenacities in the oxidized layer after oxidizing thermal cycling for instance. According to this approach, the authors have demonstrated the corner effect delays crack initiation $\left(45^{\circ}\right.$ vs $\left.90^{\circ}\right)$.

The maximum stress obtained by the simulation at the $90^{\circ} \mathrm{C}$ level has the same order of magnitude as the experimental mechanical strength of epoxy ( $80 \mathrm{MPa}$ in Fig. 3); this result is consistent with experimental results on oxidized samples at both $111 \mathrm{~h}$ and $240 \mathrm{~h}$, which showed no cracking phenomena. Although the present simulation validates the semi-analytical 1D model proposed for the quasi-semi-infinite plane case $\left(90^{\circ}\right)$, it also shows a non-monotonic stress state along the $45^{\circ}$ direction due to geometric effects that could not be reproduced by the semi-analytical model. Therefore, these results advocate the preferential use of FE simulation to account for the geometrical features of structures and their effect on the overall chemo-mechanical response and durability of thermosets.

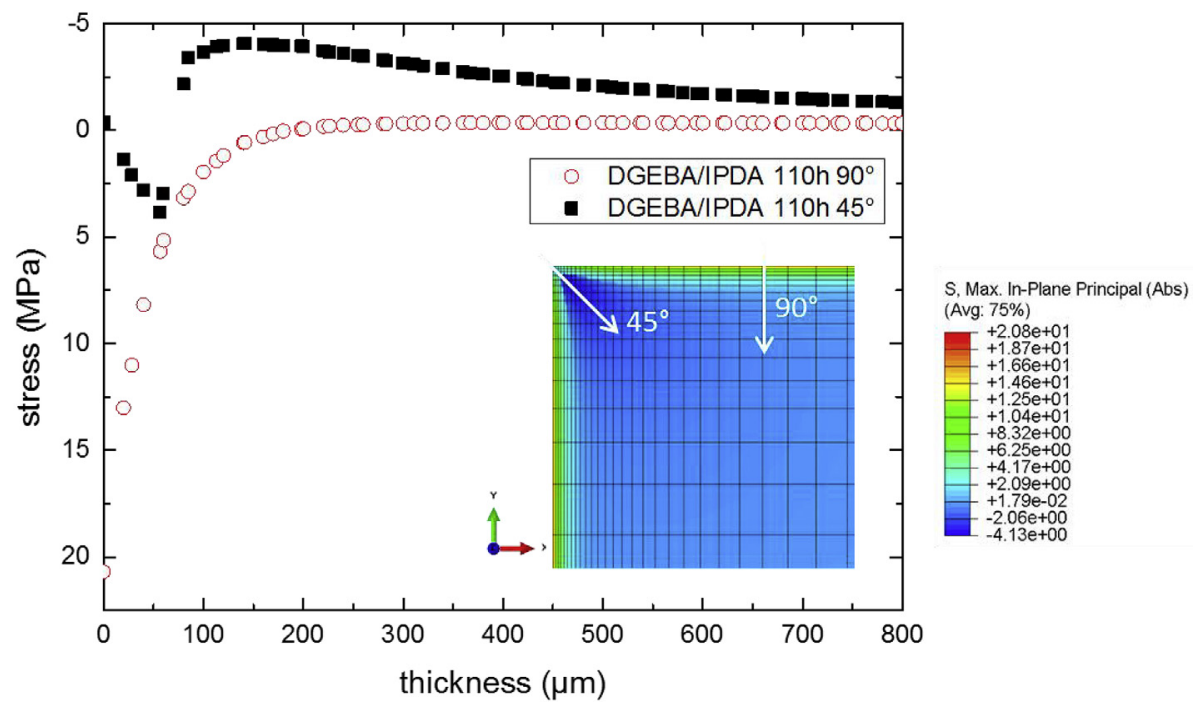

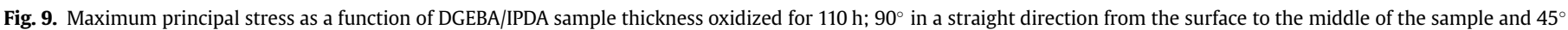
from the corner to the middle of the sample.

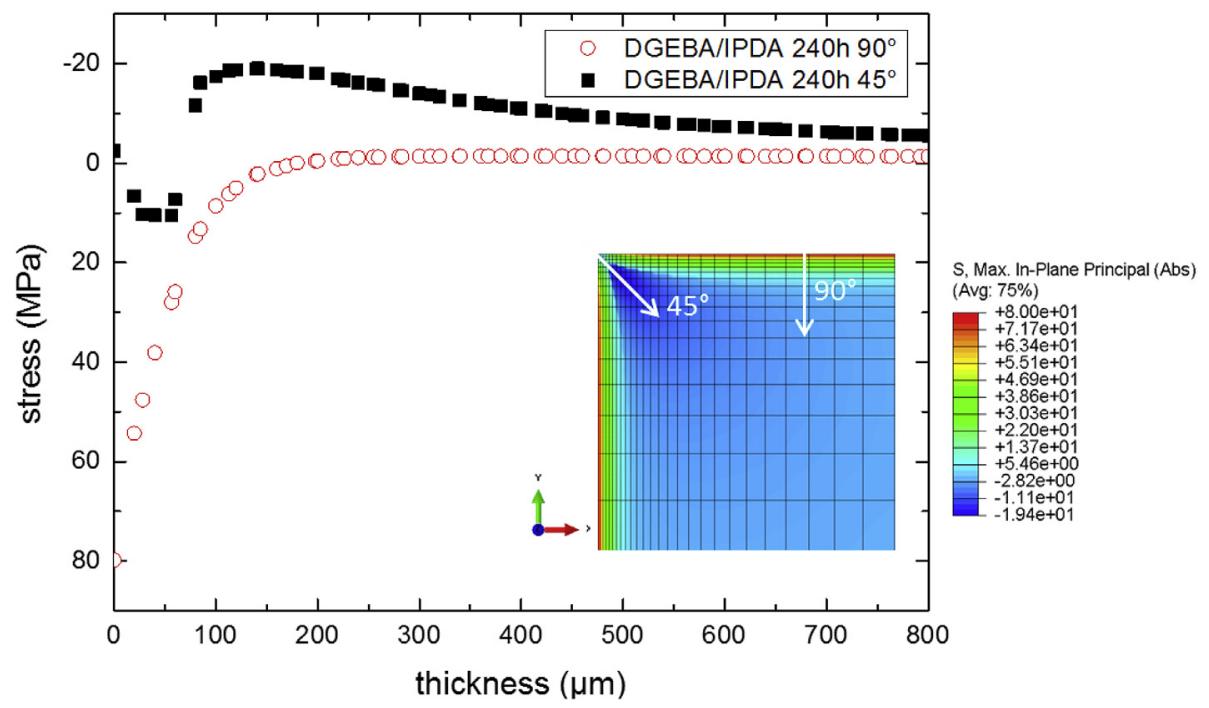

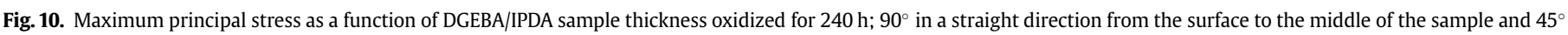
from the corner to the middle of the sample. 


\section{Conclusion}

The main purpose of the present work was to propose a methodology to predict stress field in oxidized layers at the edge of thick parts. This methodology was applied to epoxy/amine oxidation in an accelerated test condition. The main originality here was coupling kinetic modeling involving DLO mechanisms with FE simulations that include local physical and mechanical behavior changes induced by oxidation.

Kinetic modeling coupled with oxygen diffusion successfully described the appearance of the oxidized layer during exposure. More precisely, the amide profile (1D) was simulated using a model in which kinetic parameters were previously assessed on thin films, i.e., independently of amide profile formation in thick samples. Through this modeling, the amide profile can be predicted for all exposure times.

This multiscale approach required us to identify and assess different relationships such as the relation between oxidation and shrinkage, or between oxidation and mechanical properties. Although the relationships can appear quantitatively as correlations, the physical meaning of these relationships are clearly understood. In the case of epoxy/amine, shrinkage is mainly driven by mass loss associated with volatile products, while mechanical behavior modifications characterized by modulus increase are linked to sub-glass transition disappearance.

Finally, by coupling the oxidation marker profile with local shrinkage and chemo-elastoplastic behaviors associated in FE code, stress-strain states were simulated in 1D. Furthermore, 2D geometry was also investigated to evidence the influence of geometry on the stress-strain state due to DLO.

\section{Acknowledgements}

ANRT (CIFRE No 2013/0356) is gratefully acknowledged for financial support.

\section{References}

[1] T.K. Tsotsis, S.M. Lee, Long-term thermo-oxidative aging in composite materials: failure mechanisms, Compos. Sci. Technol. 58 (1998) 355-368, https:// doi.org/10.1016/S0266-3538(97)00123-1.

2] M.C. Celina, Review of polymer oxidation and its relationship with materials performance and lifetime prediction, Polym. Degrad. Stabil. 98 (2013) 2419-2429, https://doi.org/10.1016/j.polymdegradstab.2013.06.024.

[3] K.T. Gillen, M. Celina, M.R. Keenan, Methods for predicting more confident lifetimes of seals in air environments, Rubber Chem. Technol. 73 (2000) 265-283, https://doi.org/10.5254/1.3547590.

[4] A. Quintana, M.C. Celina, Overview of DLO modeling and approaches to predict heterogeneous oxidative polymer degradation, Polym. Degrad. Stabil. 149 (2018) 173-191, https://doi.org/10.1016/j.polymdegradstab.2017.11.014.

[5] L.M. Rincon-Rubio, B. Fayolle, L. Audouin, J. Verdu, A general solution of the closed-loop kinetic scheme for the thermal oxidation of polypropylene, Polym. Degrad. Stabil. 74 (2001) 177-188, https://doi.org/10.1016/S01413910(01)00154-9.

[6] L. Audouin, V. Langlois, J. Verdu, J.C.M. de Bruijn, Role of oxygen diffusion in polymer ageing: kinetic and mechanical aspects, J. Mater. Sci. 29 (1994) 569-583, https://doi.org/10.1007/BF00445968.

[7] J. Decelle, N. Huet, V. Bellenger, Oxidation induced shrinkage for thermally aged epoxy networks, Polym. Degrad. Stabil. 81 (2003) 239-248, https:// doi.org/10.1016/S0141-3910(03)00094-6.

[8] M. Gigliotti, M. Minervino, M.C. Lafarie-Frenot, Thermo-oxidative induced shrinkage in organic matrix composites for high temperature applications: effect of fibre arrangement and oxygen pressure, Compos. Struct. 146 (2016) 176-186, https://doi.org/10.1016/j.compstruct.2016.03.007.

[9] M. Gigliotti, M. Minervino, M.C. Lafarie-Frenot, Assessment of thermooxidative induced chemical strain by inverse analysis of shrinkage profiles in unidirectional composites, Compos. Struct. 157 (2016) 320-336, https:/ doi.org/10.1016/j.compstruct.2016.07.037.

[10] M. Pecora, Y. Pannier, M.-C. Lafarie-Frenot, M. Gigliotti, C. Guigon, Effect of thermo-oxidation on the failure properties of an epoxy resin, Polym. Test. 52 (2016) 209-217, https://doi.org/10.1016/j.polymertesting.2016.04.008.

[11] R.A. Assink, M. Celina, J.M. Skutnik, D.J. Harris, Use of a respirometer to measure oxidation rates of polymeric materials at ambient temperatures,
Polymer $46 \quad$ (2005) 11648-11654, https://doi.org/10.1016/ j.polymer.2005.09.069.

[12] X. Colin, L. Audouin, J. Verdu, Determination of thermal oxidation rate constants by an inverse method. Application to polyethylene, Polym. Degrad. Stabil. $86 \quad$ (2004) 309-321, https://doi.org/10.1016 j.polymdegradstab.2004.04.022.

[13] X. Colin, C. Marais, J. Verdu, A new method for predicting the thermal oxidation of thermoset matrices, Polym. Test. 20 (2001) 795-803, https:/ doi.org/10.1016/S0142-9418(01)00021-6.

[14] J. Pilař, M. Šlouf, D. Michálková, I. Šloufová, T. Vacková, J. Dybal, Pro-oxidant activity of $\alpha$-tocopherol during photooxidative degradation of polyolefins. ESRI and IR microspectroscopy studies, Polym. Degrad. Stabil. 138 (2017) 55-71, https://doi.org/10.1016/j.polymdegradstab.2017.02.008.

[15] E. Ernault, E. Richaud, B. Fayolle, Thermal oxidation of epoxies: influence of diamine hardener, Polym. Degrad. Stabil. 134 (2016) 76-86, https://doi.org/ 10.1016/j.polymdegradstab.2016.09.030.

[16] W.E. Link, K.M. Buswell, Application of infrared spectroscopy to the analysis of primary fatty amide mixtures, J. Am. Oil Chem. Soc. 39 (1962) 39-44, https:// doi.org/10.1007/BF02633348.

[17] P. Musto, G. Ragosta, P. Russo, L. Mascia, Thermal-oxidative degradation of epoxy and epoxy-bismaleimide networks: kinetics and mechanism, Macromol. Chem. Phys. 202 (2001) 3445-3458, https://doi.org/10.1002/1521 3935(20011201)202:18<3445::AID-MACP3445>3.0.CO;2-N.

[18] N. Rasoldier, X. Colin, J. Verdu, M. Bocquet, L. Olivier, L. Chocinski-Arnault M.C. Lafarie-Frenot, Model systems for thermo-oxidised epoxy composite matrices, Compos. Appl. Sci. Manuf. 39 (2008) 1522-1529, https://doi.org/ 10.1016/j.compositesa.2008.05.016.

[19] C. Damian, E. Espuche, M. Escoubes, Influence of three ageing types (therma oxidation, radiochemical and hydrolytic ageing) on the structure and gas transport properties of epoxy-amine networks, Polym. Degrad. Stabil. 72 (2001) 447-458, https://doi.org/10.1016/S0141-3910(01)00045-3.

[20] F. Delor-Jestin, D. Drouin, P.-Y. Cheval, J. Lacoste, Thermal and photochemical ageing of epoxy resin - influence of curing agents, Polym. Degrad. Stabil. 91 (2006) 1247-1255, https://doi.org/10.1016/j.polymdegradstab.2005.09.009.

[21] K. Li, K. Wang, M. Zhan, W. Xu, The change of thermal-mechanical properties and chemical structure of ambient cured DGEBA/TEPA under accelerated thermo-oxidative aging, Polym. Degrad. Stabil. 98 (2013) 2340-2346, https:// doi.org/10.1016/j.polymdegradstab.2013.08.014.

[22] E. Ernault, E. Richaud, B. Fayolle, Origin of epoxies embrittlement during oxidative ageing, Polym. Test. 63 (2017) 448-454, https://doi.org/10.1016 j.polymertesting.2017.09.004.

[23] X. Colin, A. Mavel, C. Marais, J. Verdu, Interaction between cracking and oxidation in organic matrix composites, J. Compos. Mater. 39 (2005) 1371-1389, https://doi.org/10.1177/0021998305050430.

[24] B. Fayolle, L. Audouin, G. George, J. Verdu, Macroscopic heterogeneity in stabilized polypropylene thermal oxidation, Polym. Degrad. Stabil. 77 (2002) 515-522, https://doi.org/10.1016/S0141-3910(02)00110-6.

[25] S. Terekhina, M. Mille, B. Fayolle, X. Colin, Oxidation induced changes in viscoelastic properties of a thermostable epoxy matrix, Polym. Sci. 55 (2013) 614-624, https://doi.org/10.1134/S0965545X13090058.

26] L. Heux, J.L. Halary, F. Lauprêtre, L. Monnerie, Dynamic mechanical and $13 \mathrm{C}$ n.m.r. investigations of molecular motions involved in the $\beta$ relaxation of epoxy networks based on DGEBA and aliphatic amines, Polymer 38 (1997) 1767-1778, https://doi.org/10.1016/S0032-3861(96)00694-5.

[27] E. Ernault, E. Richaud, B. Fayolle, Thermal-oxidation of epoxy/amine followed by glass transition temperature changes, Polym. Degrad. Stabil. 138 (2017) 82-90, https://doi.org/10.1016/j.polymdegradstab.2017.02.013.

28] M.C. Lafarie-Frenot, J.C. Grandidier, M. Gigliotti, L. Olivier, X. Colin, J. Verdu, J. Cinquin, Thermo-oxidation behaviour of composite materials at high temperatures: a review of research activities carried out within the COMED program, Polym. Degrad. Stabil. 95 (2010) 965-974, https://doi.org/10.1016/ j.polymdegradstab.2010.03.019.

[29] L. Olivier, N.Q. Ho, J.C. Grandidier, M.C. Lafarie-Frenot, Characterization by ultra-micro indentation of an oxidized epoxy polymer: correlation with the predictions of a kinetic model of oxidation, Polym. Degrad. Stabil. 93 (2008) 489-497, https://doi.org/10.1016/j.polymdegradstab.2007.11.012.

[30] O. Okamba-Diogo, E. Richaud, J. Verdu, F. Fernagut, J. Guilment, B. Fayolle Molecular and macromolecular structure changes in polyamide 11 during thermal oxidation - kinetic modeling, Polym. Degrad. Stabil. 120 (2015) 76-87, https://doi.org/10.1016/j.polymdegradstab.2015.06.005.

31] E.T. Denisov, I.B. Afanas'ev, Oxidation and Antioxidants in Organic Chemistry and Biology, Taylor \& Francis, Boca Raton, FL, 2005.

[32] E. Richaud, O. Okamba Diogo, B. Fayolle, J. Verdu, J. Guilment, F. Fernagut Review: auto-oxidation of aliphatic polyamides, Polym. Degrad. Stabil. 98 (2013) 1929-1939, https://doi.org/10.1016/j.polymdegradstab.2013.04.012.

[33] S. Korcek, J.H.B. Chenier, J.A. Howard, K.U. Ingold, Absolute rate constants for hydrocarbon autoxidation. XXI. Activation energies for propagation and the correlation of propagation rate constants with carbon-hydrogen bond strengths, Can. J. Chem. 50 (1972) 2285-2297, https://doi.org/10.1139/v72365.

[34] E. Richaud, F. Farcas, P. Bartoloméo, B. Fayolle, L. Audouin, J. Verdu, Effect of oxygen pressure on the oxidation kinetics of unstabilised polypropylene Polym. Degrad. Stabil. 91 (2006) 398-405, https://doi.org/10.1016 j.polymdegradstab.2005.04.043.

[35] K.T. Gillen, J. Wise, R.L. Clough, General solution for the basic autoxidation 
scheme, Polym. Degrad. Stabil. 47 (1995) 149-161, https://doi.org/10.1016/ 0141-3910(94)00105-H.

[36] E. Richaud, X. Colin, B. Fayolle, L. Audouin, J. Verdu, Induction period in the low-temperature thermal oxidation of saturated hydrocarbons: example of polyethylene, Int. J. Chem. Kinet. 40 (2008) 769-777, https://doi.org/10.1002/ kin.20347.

[37] A. Guinault, C. Sollogoub, V. Ducruet, S. Domenek, Impact of crystallinity of poly(lactide) on helium and oxygen barrier properties, Eur. Polym. J. 48 (2012) 779-788, https://doi.org/10.1016/j.eurpolymj.2012.01.014.

[38] M.C. Celina, A.R. Dayile, A. Quintana, A perspective on the inherent oxidation sensitivity of epoxy materials, Polymer 54 (2013) 3290-3296, https://doi.org/ 10.1016/j.polymer.2013.04.042.

[39] M.C. Celina, A. Quintana, Oxygen diffusivity and permeation through polymers at elevated temperature, Polymer 150 (2018) 326-342, https://doi.org/ 10.1016/j.polymer.2018.06.047.
[40] M. Gardette, A. Perthue, J.-L. Gardette, T. Janecska, E. Földes, B. Pukánszky, S. Therias, Photo- and thermal-oxidation of polyethylene: comparison of mechanisms and influence of unsaturation content, Polym. Degrad. Stabil. 98 (2013) 2383-2390, https://doi.org/10.1016/j.polymdegradstab.2013.07.017.

[41] Abaqus 6.12-3, Dassault Systèmes, 2012.

[42] I. Yakimets, D. Lai, M. Guigon, Effect of photo-oxidation cracks on behaviour of thick polypropylene samples, Polym. Degrad. Stabil. 86 (2004) 59-67, https:// doi.org/10.1016/j.polymdegradstab.2004.01.013.

[43] G. Lubineau, P. Ladevèze, D. Violeau, Durability of CFRP laminates under thermomechanical loading: a micro-meso damage model, Compos. Sci.

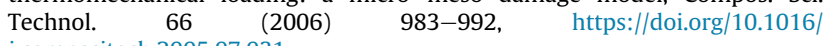
j.compscitech.2005.07.031.

[44] G. Lubineau, D. Violeau, P. Ladevèze, Illustrations of a microdamage model for laminates under oxidizing thermal cycling, Compos. Sci. Technol. 69 (2009) 3-9, https://doi.org/10.1016/j.compscitech.2007.10.042. 